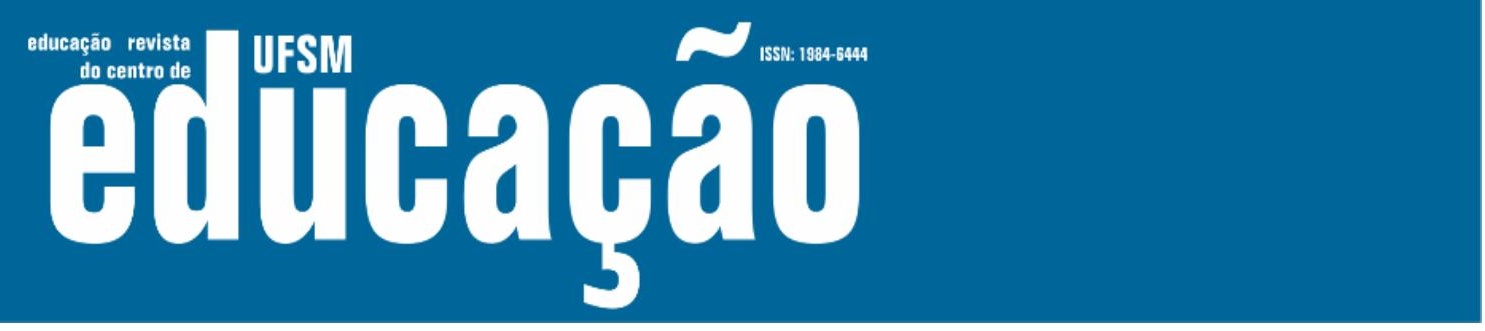

ISSN: 1984-6444 | http://dx.doi.org/10.5902/1984644443012

\title{
Formação acadêmica e vida independente: um diálogo a ser construído
}

Academic education and independent life: a dialogue to be built

\author{
Annie Gomes Redig \\ Professora Doutora da Universidade do Estado do Rio de Janeiro. Rio de Janeiro, Rio de Janeiro, \\ Brasil. \\ annieredig@yahoo.com.br - https://orcid.org/0000-0003-3610-5333
}

Recebido em 19 de março de 2020

Aprovado em 18 de agosto de 2020

Publicado em 30 de junho de 2021

\section{RESUMO}

Muito discute-se a inclusão escolar do sujeito com deficiência, mas pouco pensa-se o momento pós-escola, quais estratégias devem ser construídas para que ele termine sua escolarização com condições para esta nova etapa. Nesta direção, o presente artigo tem como finalidade discutir a construção de um Plano Individualizado de Transição, como uma estratégia pedagógica para auxiliar o processo de transição da escola para vida independente para jovens e adultos com deficiência. Este documento configura-se como um instrumento norteador do trabalho do professor, de forma a organizar a ação pedagógica e o atendimento educacional especializado, com o objetivo de auxiliar o processo de transição da escola para vida independente para estudantes com deficiência. Pensando a saída do aluno da escola, de forma que este seja capaz de inserir-se socialmente na comunidade, decidir seu percurso formativo, modalidades de Educação Profissional e inserção no mundo do trabalho. Nesse sentido, conclui-se que a individualização do ensino aliada à acessibilidade pedagógica, uma equipe capacitada e com um trabalho colaborativo, é possível que estes educandos trilhem seus caminhos nos mais diferentes níveis de ensino e vida independente.

Palavras-chave: Transição; Pessoa com deficiência; Plano Individualizado de Transição.

\section{ABSTRACT}

There is much discussion about the school inclusion of the disabled subject, but little thought is given to the post-school moment, what strategies should be constructed so that he finishes his schooling with conditions for this new stage. In this direction, this article aims to discuss, through a systematic review of the literature of the area, the construction of an Individualized Transition Plan, as a pedagogical strategy to assist 


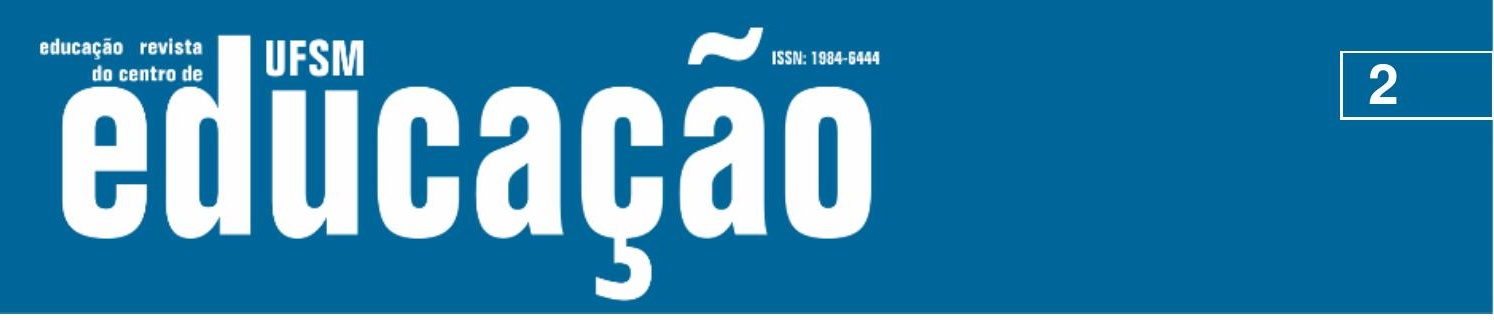

ISSN: 1984-6444 | http://dx.doi.org/10.5902/1984644443012

the transition process from school to independent living for youth and adults with disabilities. This document is an instrument that guides the work of the teacher in order to organize the pedagogical action and the specialized educational service, with the purpose of assisting the transition process from school to independent living for students with disabilities. Thinking about the student leaving the school, so that he is able to join socially in the community, decide their training course, vocational courses and insertion in the world of work. Therefore, it is concluded that the individualization of teaching allied to pedagogical accessibility, a skilled team and with a collaborative work, it is possible for these students to walk their paths in the most different levels of teaching and independent life.

Keywords: Transition; Person with disability; Individualized Transition Plan.

\section{Introdução}

A inclusão escolar de pessoas com deficiência no Brasil tem respaldo de inúmeras leis (BRASIL, 1996, 2008, 2015; entre outras) que preconizam uma escola acessível para todas as pessoas. Para que esses sujeitos com deficiência, principalmente os com deficiência intelectual e múltiplas, tenham possibilidade de inserção no mundo do trabalho, é necessário pensar uma escola que vá além do ensino de conteúdos acadêmicos, mas que entenda que o desenvolvimento de competências é importante para auxiliar no aprimoramento de habilidades para vida independente.

O objetivo final da escola não deve ser apenas a entrada no ensino superior, visto que há outras opções ao sair da escola e que passar para uma graduação não garante a conclusão deste curso, inserção no mercado de trabalho, inclusão social e independência. Nessa perspectiva, pensar em uma escola que valorize as habilidades, interesses e capacidades dos sujeitos é uma forma de possibilitar o desenvolvimento de habilidades para que esse indivíduo possa ter uma vida independente.

Redig (2019) aponta que nenhuma pessoa é totalmente independente, sempre é preciso algum suporte para auxiliar em um aspecto do cotidiano, como por exemplo, ir à um lugar novo, é necessário aprender o caminho e esse suporte pode ser uma pessoa que ensinará o melhor trajeto ou a internet. Então, o objetivo deve 


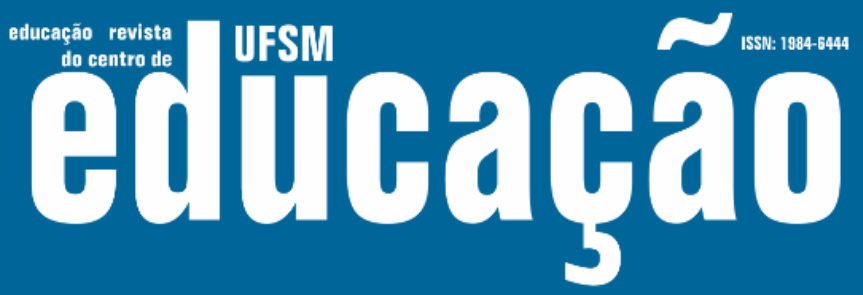

ISSN: 1984-6444 | http://dx.doi.org/10.5902/1984644443012

ser que esse sujeito possa ser o mais independente possível. Para isso, é essencial o desenvolvimento de habilidades que englobem todos os aspectos do desenvolvimento e do cotidiano, como habilidades para vida diária, cuidados com a casa, higiene, noções de cidadania, locomoção, tomada de decisão, moradia independente, mundo do trabalho, lazer, relacionamentos, entre outros.

Nessa direção, para que a escola auxilie nesse processo é fundamental pensar em estratégias que possibilitem a transição da escola para a vida adulta, ou seja, para o momento em que o aluno sairá da escola e, para isso, a elaboração de instrumentos que organizam a prática pedagógica de forma a contemplar a individualização do ensino é um dos caminhos. Com isso, o Plano de Ensino Individualizado - PEI (MASCARO, 2017; TANNÚS-VALADÃO, 2011) que constrói um currículo diferenciado e personalizado para o aluno com deficiência é uma proposta que vai na direção de uma escola inclusiva e consequentemente, o Plano Individualizado de Transição (PIT) permite a organização desse processo de transição.

Sendo assim, o objetivo deste trabalho ${ }^{1}$ é o de discutir o PIT como um instrumento norteador para auxiliar o trabalho desenvolvido com os alunos com deficiência, visando a saída da escola com escolarização adequada, vida independente que permita condições de inserção no mundo do trabalho. Entendemos que, ao consideramos o termo vida independente, contemplamos todos os aspectos que fazem parte da vida do sujeito, inclusive a sua inserção no mercado de trabalho, progressão profissional, relacionamentos de amizade e amorosos, acesso a níveis mais elevados de escolarização, entre outros.

\section{Plano Individualizado de Transição}

A proposta da inclusão escolar para pessoas consideradas público-alvo da Educação Especial ${ }^{2}$ tem como finalidade possibilitar o acesso à escola. Entretanto, 0 que observamos é que esse acesso, como para o restante da população, não acontece em todos os níveis de ensino. De acordo com o quadro abaixo, a partir dos dados das sinopses das estatísticas do censo escolar publicados pelo Instituto 


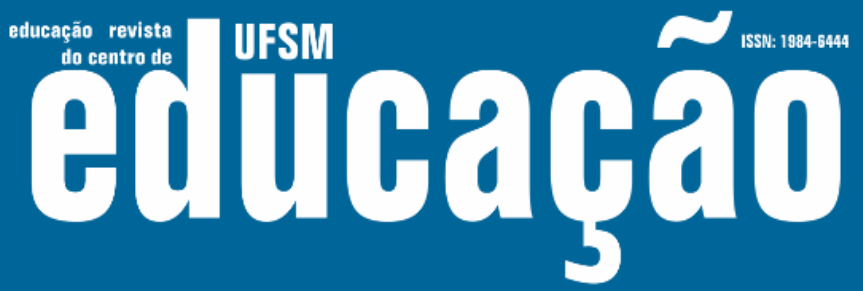

ISSN: 1984-6444 | http://dx.doi.org/10.5902/1984644443012

Nacional de Estudos e Pesquisas Educacionais Anísio Teixeira (INEP), observamos a diminuição do número de matrículas destes educandos nos diferentes níveis de ensino.

Quadro 1 - Tabela demonstrativa das matrículas de alunos com deficiência em turma comum no Brasil

\begin{tabular}{|c|c|}
\hline Matrículas de alunos com deficiência em turma comum & no Brasil (censo 2018) \\
\hline Total de alunos com deficiência no Brasil em turma comum ${ }^{3}$ & 1.014 .661 \\
\hline Educação Infantil & 81.254 \\
\hline Ensino Fundamental & 741.426 \\
\hline Ensino Fundamental I & 421.560 \\
\hline Ensino Fundamental II & 319.856 \\
\hline Ensino Médio & 115.051 \\
\hline Ensino Médio Propedêutico & 109.454 \\
\hline Ensino Médio Normal/Magistério & 729 \\
\hline Curso Técnico Integrado & 4.868 \\
\hline Educação de Jovens e Adultos & 72.030 \\
\hline Ensino Fundamental & 57.364 \\
\hline Ensino Médio & 14.666 \\
\hline Ensino Superior (EAD e Presencial) & 38.272 \\
\hline
\end{tabular}

Fonte: INEP (2018a, 2019)

De acordo com o quadro 1 , o número de matrículas de crianças com deficiência na Educação Infantil é baixo, mas isso pode ser devido à idade dos alunos e a dificuldade no diagnóstico precoce da deficiência. Desta forma, esse número pode não ser equivalente à realidade. Um aspecto impressionante, nesses dados, é a diminuição de matrícula no Ensino Médio e Superior. A cada mudança de etapa na escolarização deste alunado, o número de matrículas diminui, seja do Ensino Fundamental I para o Fundamental II, Médio e assim por diante. É uma queda brusca de matrículas e essa situação se repete na Educação de Jovens e Adultos (EJA). 


\section{ح

ISSN: 1984-6444 | http://dx.doi.org/10.5902/1984644443012

Segundo Dantas (2013, p.158),

Logo, é possível afirmar que a inclusão escolar conquistada na Educação Infantil e na Educação Básica sofre um processo de interrupção permanente, quando as pessoas com deficiência intelectual chegam à fase adulta, havendo um retorno às instituições especializadas, ou permanência forçada em casa, sem ao menos contar com o contato familiar no cotidiano, uma vez que todos os adultos da família encontram-se, de alguma forma, envolvidos com a formação educacional e/ou trabalho.

Com relação ao ensino superior, sabemos das dificuldades enfrentadas pelas pessoas com deficiência de ingressar em cursos de graduação, pela rigorosidade das avaliações (ENEM e vestibulares) e falta de acessibilidade para a realização destas provas. Podemos questionar-nos também sobre a inserção destes sujeitos em cursos profissionalizantes e consequentemente no mercado de trabalho, pois é exigido, na maioria dos casos, o término dos estudos (REDIG, 2016).

Entretanto, muitos jovens e adultos com deficiência, principalmente se pensarmos os que apresentam deficiência intelectual e múltipla, estão em instituições especializadas, entrelaçando o seu percurso formativo entre escola comum e especial. Os dados estatísticos brutos não revelam a qualidade desse ensino, pois estar matriculado em turma comum não garante o aprendizado de conteúdos acadêmicos de acordo com a idade e série.

Nas trajetórias, é evidenciada a dificuldade da efetivação de uma educação inclusiva, visto que não foram oferecidas condições pedagógicas favoráveis ao aprendizado dos participantes, o que culminou em longos períodos de permanência em uma mesma série, ocasionando disparidade entre idade e série. (LEITE; CAMPOS, 2018, p.19).

Para que uma escola seja considerada inclusiva, possibilitando acesso, permanência e construção de conhecimento, é preciso suporte, formação de recursos humanos, investimento, acessibilidade física e pedagógica, mas é necessário também que repense o seu currículo e suas práticas pedagógicas de forma que permita a individualização do ensino a partir das necessidades, interesses e demandas de cada aluno. Portanto, a escola deve possibilitar o aprendizado de conteúdos acadêmicos e ser um caminho, estratégia, etapa de transição para o 


\section{$\sim$

ISSN: 1984-6444 | http://dx.doi.org/10.5902/1984644443012

momento pós-escola, proporcionando o desenvolvimento de habilidades que permitam o seu desenvolvimento para viver em sociedade.

O PIT é um instrumento que auxilia na organização do percurso formativo para a vida independente. De acordo com Redig (2019, p.8):

O PIT é um documento para organizar o processo de transição do aluno com deficiência da escola para a vida adulta e/ou mundo do trabalho, vida independente, sendo um dos eixos do PEI. Desta forma, esse processo será organizado por uma equipe, a mesma do $\mathrm{PEI}$, incluindo, obrigatoriamente, $\mathrm{o}$ aluno.

Para a construção do PIT assim como o $\mathrm{PEI}^{5}$, é fundamental que haja uma equipe composta pelos profissionais envolvidos no processo, como os professores da Educação Especial, da turma comum, família, o aluno e demais profissionais da saúde e educação (REDIG, 2019). Para a elaboração do PIT é imprescindível que o aluno com deficiência faça parte desta equipe, pois somente ele poderá informar quais os seus interesses e estipular metas para o momento pós-escola. Essa meta para etapa pós-escola tem que considerar cursos de formação profissional, inclusão social e autonomia considerando os objetivos de vida do indivíduo. Planejar o processo de transição é pensar em um projeto de vida para curto, médio e longo prazo. Portanto, a escola precisa estabelecer parcerias com instituições profissionalizantes para auxiliar no processo de transição. Leite e Campos (2018, p. 28), ao ouvir alunos com deficiência da EJA, apontaram que

\footnotetext{
Os relatos observados por meio das entrevistas foram muito gratificantes, pois todos os participantes matriculados na EJA, nível Ensino Médio, demostraram a pretensão de continuar com os estudos, embora alguns não tenham decidido o que fazer ou, ainda, manifestem insegurança por medo de não conseguir atuar no mercado de trabalho devido à deficiência; percepção devida, provavelmente, a insucessos e fracassos vivenciados.
}

Para a inserção no mundo do trabalho, na maioria dos casos há exigência do ensino médio completo para trabalhar (REDIG, 2014, 2016), como escolaridade mínima para a contratação. E, se pensarmos na realidade de jovens e adultos com deficiência, principalmente os com deficiência intelectual e múltiplas, oriundos de 


\section{usm Althapat

ISSN: 1984-6444 | http://dx.doi.org/10.5902/1984644443012

\section{Escolarização de pessoas com deficiência no Ensino Médio}

De acordo com o quadro 1 , os dados do INEP mostram uma redução quantitativa no número de matrículas de alunos com deficiência no Ensino Médio. Isso pode acontecer por diversos fatores, como retenção no ensino fundamental, transferência para instituições especializadas ou até mesmo saída da escola. O que observamos (MASCARO, 2017; PLETSCH, 2014) é que quando o estudante com deficiência, principalmente o que apresenta deficiência intelectual, avança nas etapas de ensino, em alguns casos, o conhecimento apreendido não é compatível com a idade $x$ série, apresentando defasagem no seu aprendizado e nos conteúdos acadêmicos. E, ao ingressar no Ensino Médio, vem outra pergunta: o que fazer quando finalizar essa etapa do ensino?

\footnotetext{
Embora esses alunos já estejam matriculados na escola regular, é necessário mais investimento para que aconteça "participação e a aprendizagem", principalmente dos alunos com deficiência intelectual, os quais muitas vezes, ainda são considerados incapazes de aprender devido à condição biológica da deficiência. (MENDES; HOEPERS; AMARAL, 2015, p.71).
}

Pela nossa experiência, percebemos que os sujeitos com deficiência, principalmente aqueles com deficiência intelectual e múltipla, matriculados em classes e escolas especiais, permanecem nestes espaços por anos a fio, sem um prazo para terminar seus estudos e sem qualquer certificação dessa escolarização. É um ciclo vicioso, que reforça o estereótipo de incapacidade do aluno, mas que, de certa forma, fortalece a manutenção do status quo das instituições especializadas, fazendo com que os professores e os responsáveis pelos alunos acomodem-se com a rotina e situação. Em um estudo sobre preparação para o trabalho de jovens com deficiência intelectual, matriculados em uma escola especial, Mascaro (2012) mostrou, entre outros aspectos, a dificuldade dos pais de projetarem um futuro para seus filhos fora da escola. 


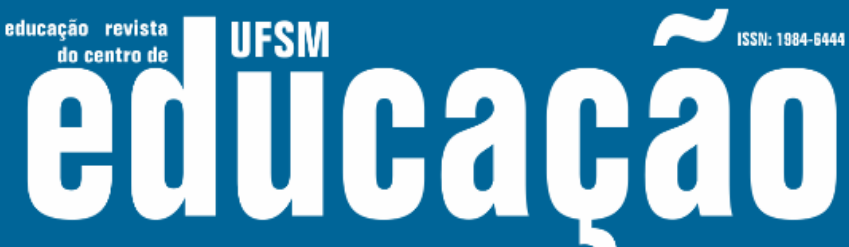

ISSN: 1984-6444 | http://dx.doi.org/10.5902/1984644443012

Quadro 2 - Tabela demonstrativa das matrículas de alunos com deficiência no Ensino Médio no Brasil.

\begin{tabular}{|c|c|c|c|c|}
\hline \multicolumn{5}{|c|}{ Matrículas de alunos com deficiência no Ensino Médio no Brasil } \\
\hline Ano & Total & $\begin{array}{c}\text { Ensino Médio } \\
\text { Propedêutico }\end{array}$ & $\begin{array}{c}\text { Ensino Médio } \\
\text { Normal/Magistério }\end{array}$ & $\begin{array}{c}\text { Curso Técnico Integrado } \\
\text { (Ensino Médio Integrado) }\end{array}$ \\
\hline 2018 & 115.051 & 109.454 & 729 & 4.868 \\
\hline 2017 & 94.274 & 90.157 & 698 & 3.419 \\
\hline 2016 & 75.059 & 71.927 & 599 & 2.533 \\
\hline 2015 & 65.757 & 63.136 & 585 & 1.655 \\
\hline 2014 & 57.754 & 55.541 & 558 & 1.323 \\
\hline 2013 & 48.589 & 46.709 & 557 & 842 \\
\hline 2012 & 43.589 & 41.797 & 654 & 717 \\
\hline 2011 & 34.278 & 32.816 & 620 & 719 \\
\hline 2010 & 28.667 & 27.231 & 719 & \\
\hline
\end{tabular}

Fonte: INEP (2011, 2012, 2013, 2014, 2015, 2016, 2017, 2018b, 2019).

Observamos no quadro 2, a partir dos dados das sinopses das estatísticas do censo escolar publicadas pelo INEP, um aumento significativo de matrículas de alunos com deficiência em turmas comuns no Ensino Médio. Entretanto, apenas por estes dados, não temos como saber se estes estudantes finalizaram seus cursos e se estão em outras etapas de escolarização e/ou mercado de trabalho. Outro aspecto que vale enfatizarmos é que, mesmo com um aumento nas matrículas, isso não garante um processo de ensino-aprendizagem adequado e nem suportes de Atendimento Educacional Especializado de qualidade para esses sujeitos. Porém, percebemos que independentemente das variáveis, as pessoas com deficiência estão chegando nessa etapa de ensino e precisam ser vistas e, para isso, é necessária oferta de suportes e programas individualizados para que essa escolarização seja bem-sucedida.

Lima e Mendes (2008) desenvolveram uma pesquisa com pais de jovens com deficiência intelectual, matriculados em turmas comuns, e constataram que a maioria 


\section{Althaห̧ão}

ISSN: 1984-6444 | http://dx.doi.org/10.5902/1984644443012

dos pais entrevistados era contra a terminalidade específica. Aqueles que concordavam com essa proposta argumentavam que assim, seus filhos poderiam receber, pelo menos, um certificado. Para alunos matriculados em classes e escolas especiais, essa certificação é de grande valia, visto que não há diplomação de acordo com o segmento concluído, como na escola regular. Os responsáveis apontaram a importância do certificado para a inserção no mundo do trabalho. Entretanto, é importante ressaltar que esse tipo de certificado seria diferente do diploma de conclusão de curso, pois, no certificado, estaria apontando o nível real de conhecimento alcançado pelo sujeito e não, necessariamente, o currículo acadêmico proposto pela escola. Seguindo essa ideia, poderiam ser ofertadas, pela instituição escolar, novas alternativas de aprendizagem para esse alunado.

Essas autoras enfatizam a necessidade de que as práticas educacionais e as avaliações considerem a pessoa com deficiência em suas singularidades, possibilitando um acompanhamento da sua aprendizagem ao longo do processo, mensurando os sucessos e os insucessos. Nas palavras das autoras (LIMA; MENDES, 2008, p.203), "parece reforçar a crença na força de um diploma como garantia de se conseguir a inserção no mundo do trabalho, mesmo que esse carregue consigo a ênfase na diferença de quem o recebe, o que as famílias parecem não perceber".

Esta discussão vem de encontro com a proposta do PIT e, consequentemente, com a customização do trabalho, no qual a partir das habilidades do sujeito, experiências e interesses aliada as necessidades e demandas da empresa é possível pensar em atividades laborais customizadas (REDIG, 2014, 2016). De acordo com esse conceito, não é obrigatoriamente preciso que o sujeito com deficiência tenha diplomas do Ensino Médio, Ensino Superior ou outro curso, mas sim uma preparação que vá ao encontro com suas habilidades e interesses de trabalho. 


\section{تilfoarẫ}

ISSN: 1984-6444 | http://dx.doi.org/10.5902/1984644443012

\section{Programa de Transição e construção do PIT}

Para a elaboração de um programa de transição, é necessário que a equipe escolar esteja organizada para pensar em estratégias que favoreçam o processo de transição da escola para a vida independente. Redig (2019) sugere que a construção desse documento inicie quando o aluno alcançar 14 anos de idade, dependendo da situação pode ser antes, e que o Atendimento Educacional Especializado contemple o desenvolvimento de habilidades para uma vida independente. $\mathrm{O}$ trabalho desenvolvido pelo Atendimento Educacional Especializado na sala de recursos multifuncional pode ser organizado de forma que planeje o momento pós-escola, ou seja, pensar o esse educando fará ao sair da escola e o que precisará aprender para alcançar os seus objetivos.

Desta forma, a equipe de profissionais envolvida precisa estar preparada e capacitada para pensar em estratégias diferenciadas e individualizadas para os alunos com deficiência no processo de transição para o momento pós-escola (NASCIMENTO, 2020). É necessária uma formação docente continuada e em serviço que relacione a teoria com a prática, a partir da demanda do professor e de sua realidade.

Há inúmeras variáveis que contribuem para o distanciamento entre o discurso (teórico) que reconhece a colaboração docente como fator imprescindível para promover a escolarização de alunos com deficiências e as ações (prática) que, efetivamente, se materializam quando esses atores interagem no cotidiano escolar. (GLAT, 2018, p.13).

A elaboração de planos individualizados é uma estratégia para organizar e normatizar a prática pedagógica e auxiliar os docentes nas ações do cotidiano escolar e no processo de ensino-aprendizagem de alunos com deficiência. Desta forma, facilita vislumbrar e relacionar a teoria com a prática e consequentemente a avaliação da metodologia e planejamentos realizados, além da evolução do estudante.

Nessa direção, pensando em um programa de transição e no PIT, estes precisam focar no desenvolvimento de competências para os diferentes aspectos da 


\section{N

ISSN: 1984-6444 | http://dx.doi.org/10.5902/1984644443012

vida, como: habilidades acadêmicas, sociais, autodefensoria/autogestão, laborais, vida independente e cidadania. Para tal, é preciso que a equipe do PIT formada por docentes da Educação Especial e de turma comum esteja engajada com a família, demais profissionais, comunidade e com o próprio aluno, respeitando seus interesses e desejos e potencializando suas capacidades. Permitir que o sujeito com deficiência seja o protagonista da sua vida é favorecer o seu crescimento pessoal.

Sendo assim, Kohler, Gothberg, Fowler e Coyle (2016) informam a taxonomia de um programa de transição que é composto por cinco categorias: planejamento focado no estudante; engajamento da família; estrutura do programa; colaboração entre instituições e desenvolvimento do estudante. Nesta direção, percebemos que é essencial o conhecimento das competências e dificuldades do sujeito pelos docentes e profissionais envolvidos e pelo próprio aluno para que, assim, possamos estruturar todo o programa que a partir dos interesses do discente organizaremos o processo de transição envolvendo o estudante, família, escola e possíveis instituições parceiras, relacionando o aprendizado acadêmico, experiências sociais, profissionais, etc, com as metas futuras. 


\section{uss

ISSN: 1984-6444 | http://dx.doi.org/10.5902/1984644443012

Figura 1 - Taxonomia de um programa de transição

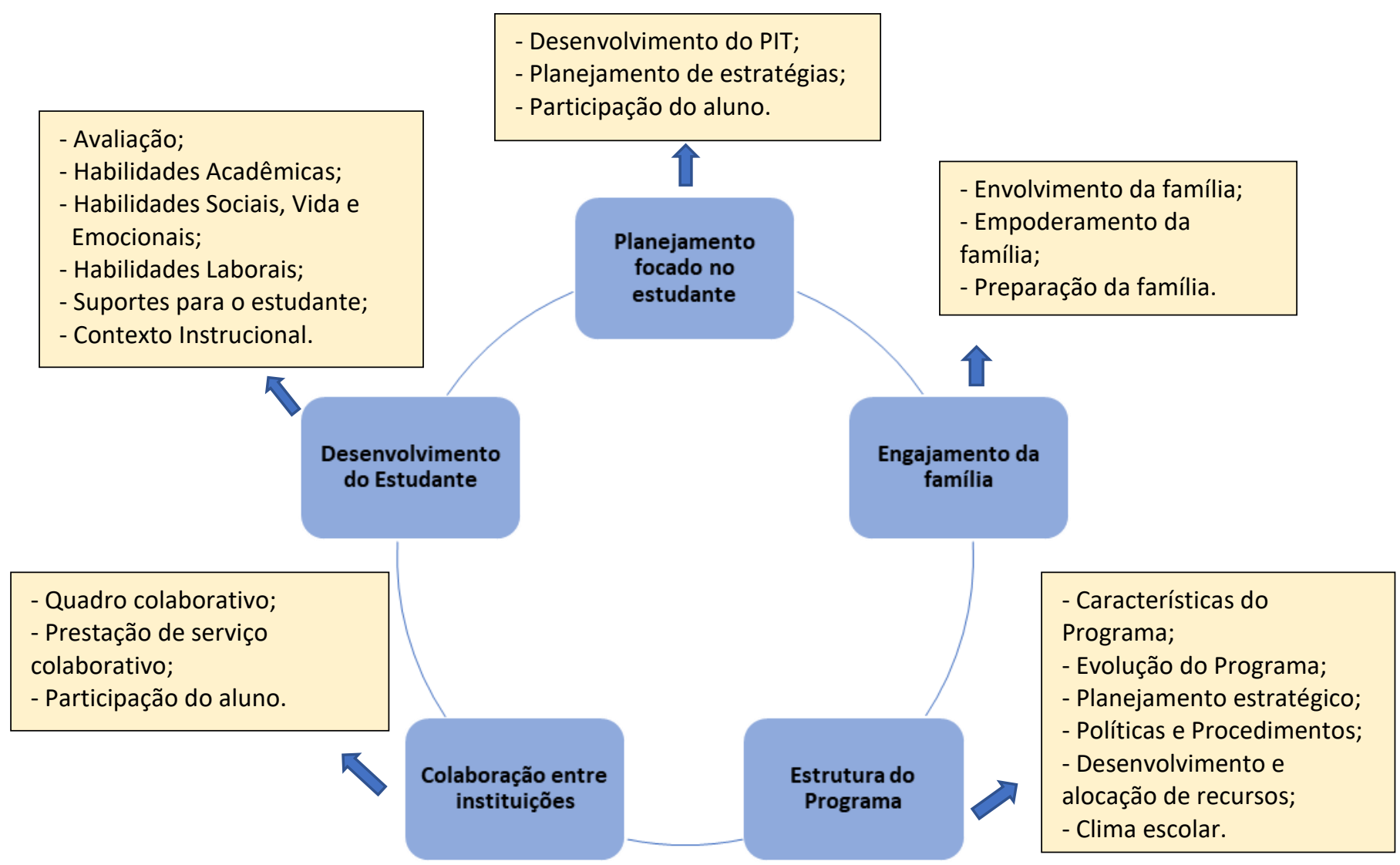

Fonte: Adaptado de Kohler, Gothberg, Fowler e Coyle (2016, p.3). Tradução livre.

De acordo com a figura 1, percebemos que, sem o engajamento destas cinco categorias, não é possível o desenvolvimento de um programa de transição. Isso significa que para o sucesso deste processo é preciso que a família, escola, aluno e demais profissionais realizem um trabalho colaborativo. Segundo Fânzeres (2017, p.18), a transição para a vida adulta "prolonga-se por todo o ciclo de vida da pessoa, envolvendo um projeto de vida que está em constante atualização".

Para a construção de um programa de transição e, consequentemente, o PIT, é necessário fazer uma avaliação do processe de transição, que segundo o documento Transition Assessment (VIRGINIA DEPARTMENT OF EDUCATION, 2014) essa avaliação é importante para descobrir as opções de cursos, atividades, que o sujeito poderá fazer ao sair da escola. Isso significa verificar as possibilidades 


\section{Autนaดูลิ}

ISSN: 1984-6444 | http://dx.doi.org/10.5902/1984644443012

de continuidade dos estudos em diferentes cursos profissionais, vida independente e inserção em atividades laborais. Dessa forma, será possível auxiliar o estudante com deficiência a conhecer-se melhor, permitindo que ele responda às seguintes questões:

- Quem eu sou?

- Quais são os meus talentos e interesses?

- O que eu quero para minha vida, agora e no futuro?

- Quais são algumas demandas da vida que posso encontrar agora?

- Quais são as principais barreiras para conseguir o que eu quero da escola e da minha comunidade?

- Quais são as minhas opções na escola e na comunidade para me preparar para o que eu quero, agora e no futuro? (VIRGINIA DEPARTMENT OF EDUCATION, 2014, p.4). ${ }^{6}$

É importante associar o desenvolvimento das competências e habilidades pessoais com o aprendizado de conteúdos acadêmicos para estabelecer quais os objetivos para o futuro (REDIG, 2019). As metas estipuladas no PIT devem estar de acordo com a idade do aluno. $O$ documento elaborado pelo Center on Transition Innovations (CTI, 2018), da Virginia Commonwealth University, informa que os dez indicativos de sucesso no processo de transição são: 1) Inclusão; 2) Diploma/Certificação; 3) Experiência de trabalho remunerado (pode ser ainda na escola); 4) Habilidades de vida independente e Autocuidado; 5) Suporte ao estudante com deficiência (enfatizamos o serviço do AEE); 6) Programa de Transição; 7) Autogestão; 8) Habilidades Sociais 9) Orientação vocacional/Orientação para carreira, trabalho e 10) Envolvimento dos responsáveis. O desenvolvimento de apenas uma ou duas dessas áreas não garantirá o suporte necessário para que o jovem e adulto com deficiência consiga as habilidades para a transição da escola para a vida independente. Para que o processo de transição tenha êxito, é preciso que todas essas áreas estejam interligadas, por isso, deve-se desenvolver um programa estruturado ao longo do período escolar do sujeito. Desta forma, é importante o investimento em políticas públicas, formação de professores e práticas pedagógicas diferenciadas em todas as áreas. 


\section{HSM Eulloarat}

ISSN: 1984-6444 | http://dx.doi.org/10.5902/1984644443012

Para o sucesso do processo de transição no momento pós-escola é fundamental que o aluno esteja engajado no planejamento e aplicação do seu PIT e, para isso, é preciso ter alta expectativa, o planejamento ser centrado no estudante, oferecer suportes social, emocional e de aprendizagem, auxiliar o educando a tomar suas decisões e informá-lo de suas opções (REDIG, 2019; U.S. DEPARTMENT OF EDUCATION, 2017).

Nesta direção, após a avaliação e estruturação das etapas, procedimentos e suportes que a escola oferece para a inclusão de alunos com deficiência, pode-se pensar em elaborar o PIT. Para isso, é imprescindível avaliar os indicadores inclusivos que norteiam o trabalho desenvolvido na escola e a equipe, o estudante e a família devem estar engajados nesse processo. Outro aspecto importante é conhecer o PEI do sujeito com deficiência e sua trajetória escolar, aprendizados acadêmicos e desenvolvimento.

Desse modo, será possível traçar o Perfil Pessoal Positivo - PPP (REDIG, 2012, 2014, 2016), do educando com deficiência. Este consiste na utilização de um inventário de habilidades (onde o sujeito informa quais suas dificuldades, interesses, o que sabe fazer, seus pontos fortes e fracos), com o objetivo de visualizar as capacidades e potencialidades do sujeito (LUECKING, 2012). Então, pode-se "transformar/ressignificar" características negativas em positivas, como, por exemplo, a hiperatividade em energia (MARTIN-LUECKING, 2012). A ênfase nas características positivas das pessoas com deficiência tem a finalidade de reforçar, por parte dos empregadores, a noção de que todos podem trabalhar. Na construção do PPP, é importante destacar as qualidades do indivíduo ao invés do que ele não pode realizar, como acontece, muitas vezes, na escola (tanto especial quanto regular) (REDIG, 2012, 2014, 2016). Segundo Leite e Campos (2018, p.26), "a motivação dos estudantes é importante aliado no processo educacional, pois pode desencadear nos indivíduos aspectos de confiança para atividades do cotidiano escolar e influenciar diretamente no processo de aprendizagem dos estudantes".

Nessa direção, com os dados coletados, equipe formada e os objetivos acordados é o momento de elaborar o PIT. Vale ressaltar que o aluno deve estar familiarizado com o PIT e seus desdobramentos. Dessa maneira, com o inventário 


\section{Authaดูã}

ISSN: 1984-6444 | http://dx.doi.org/10.5902/1984644443012

de habilidades acadêmicas e sociais, inventário de interesses (onde ele poderá informar/descobrir o que realmente gosta de fazer) e o PPP do aluno poderemos construir o PIT, visando o desenvolvimento de competências para sua inserção em atividades laborais. Soriano (2006) aponta que o PIT é um documento em que registra o passado, presente e perspectivas de futuro do sujeito.

O PIT é formado por cinco etapas ${ }^{7}$ :

1. Identificação do aluno;

2. Caracterização do aluno e família (situação familiar, desejos e expectativas);

3. Aspectos do aluno em relação ao conhecimento acadêmico, interações e relacionamentos interpessoais, autonomia, atitudes sociais;

4. Objetivos gerais e específicos do PIT para o aluno (emprego, educação, vida independente, transporte, atividades da vida diária, etc);

5. Previsão de saída da escola e com qual certificação;

6. Perspectivas futuras (lembrando, que as metas são de acordo com a idade e necessidades do educando).

Da mesma forma que o PEI deve ser avaliado periodicamente (Mascaro, 2017), o PIT também deve ser, para que avalie se as estratégias e metas traçadas estão adequadas e se foram alcançados os resultados desejados para que, assim, possa se pensar nas próximas etapas. Com isso, é fundamental um plano de ação do PIT.

Quadro 3: Plano de Ação do PIT.

\begin{tabular}{|c|c|c|c|c|c|}
\hline Categorias & $\begin{array}{c}\text { Definição operacional } \\
\text { e características } \\
\text { essenciais do } \\
\text { programa } \\
\text { (O que será } \\
\text { trabalhado?) }\end{array}$ & $\begin{array}{c}\text { Etapas de } \\
\text { ação }\end{array}$ & $\begin{array}{c}\text { Equipe } \\
\text { responsável, } \\
\text { Profissionais e } \\
\text { pessoas } \\
\text { envolvidos }\end{array}$ & $\begin{array}{c}\text { Tempo } \\
\text { de } \\
\text { aplicação }\end{array}$ & Avaliação \\
\hline & & & & & \\
\hline
\end{tabular}

Fonte: A autora (2019). 


\section{Autนaดูลิ}

ISSN: 1984-6444 | http://dx.doi.org/10.5902/1984644443012

O objetivo do plano de ação é que, após a definição das metas no PIT, este instrumento sirva para organizar a prática docente, informando qual(is) categoria(s) serão contempladas, como, por exemplo, habilidades sociais, autogestão, experiência de trabalho, entre outras. Em seguida, de acordo com a categoria serão definidas as características do programa, ou seja, dentro da categoria; o que será trabalhado naquele período estabelecido; quais as etapas da ação, como será executado e quem fará parte da equipe e das etapas. No final, do período de aplicação este plano será avaliado e repensado.

Vale ressaltar, que, para a construção do PIT, é preciso que os docentes estejam capacitados para a elaboração e avaliação deste instrumento pedagógico. Sem uma formação adequada, esses materiais não serão utilizados da melhor maneira. Os professores de Atendimento Educacional Especializado devem ter o PIT como meta para o desenvolvimento do aluno e sua saída da escola, auxiliando o docente da turma comum, na elaboração de práticas pedagógicas individualizadas e sendo uma ponte com a comunidade, na qual o estudante iniciará seu processo de transição na escola, aprendizagem profissional e construindo seu projeto de vida. Dessa forma, o educando com deficiência, terá uma escolarização estruturada e com perspectivas de ações para além dos muros da escola.

Fânzeres (2017, p.21) aponta alguns aspectos que facilitam o desenvolvimento de um programa de transição e a construção do PIT:

a implementação de políticas legislativas flexíveis; a aplicação de regulamentações nacionais e projetos locais; a partilha de informação aos empregadores; o respeito pelas aspirações e os desejos dos jovens, bem como o envolvimento dos alunos e da família; a aplicação de estratégias educacionais claras e perfil de competências; existência de opções abertas e informação clara e de uma rede de apoio e o envolvimento dos empregadores e organizações de emprego.

Este autor também informa que o PIT é necessário e eficaz no auxílio ao sujeito com deficiência para adquirir habilidades laborais e a sua colocação no mercado de trabalho. Entretanto, vale lembrar que é fundamental a formação dos professores e conscientização dos empregadores para que esse processo dê certo. 


\section{T uss

ISSN: 1984-6444 | http://dx.doi.org/10.5902/1984644443012

Nesta direção, para a elaboração do PIT é preciso que a equipe, como já comentado, realize um trabalho colaborativo de forma a oferecer os suportes necessários. Para isso, cada integrante da equipe, a partir dos objetivos traçados, estipulará a sua função no processo, como, por exemplo, o professor do Atendimento Educacional Individualizado elaborará um trabalho na sala de recursos voltado para o autoconhecimento e desenvolvimento de habilidades baseados nos interesses do educando, se ele gosta de dançar e pretende trabalhar como professor de dança, quais habilidades são necessárias para isso? O que o aluno ainda precisa aprender para inserir-se no mercado de trabalho no futuro, como autonomia de locomoção e todos os aspectos que envolvem alcançar esta meta.

Então, o docente da turma comum, de Artes, pode exemplo, pode auxiliar na construção de conhecimento de diferentes formas de expressão, o de Geografia, a elaboração de mapas para auxiliar na autonomia de locomoção e, com isso, cada professor determinará como trabalhar de acordo com o que foi proposto e com o conteúdo da série. O aluno deve estar ciente de todo processo e, inclusive, se possível, organizar as reuniões para discutir o seu PIT, pensar em quais estratégias podem ser utilizadas, etc. A família deve ampliar o trabalho desenvolvido na escola para a residência e demais espaços e assim por diante. 


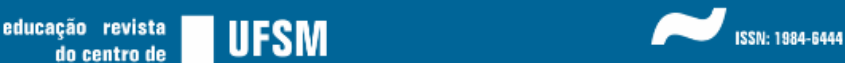

ISSN: 1984-6444 | http://dx.doi.org/10.5902/1984644443012

Figura 2 - Figura ilustrativa sobre os suportes que devem ser oferecidos na implementação do PIT.

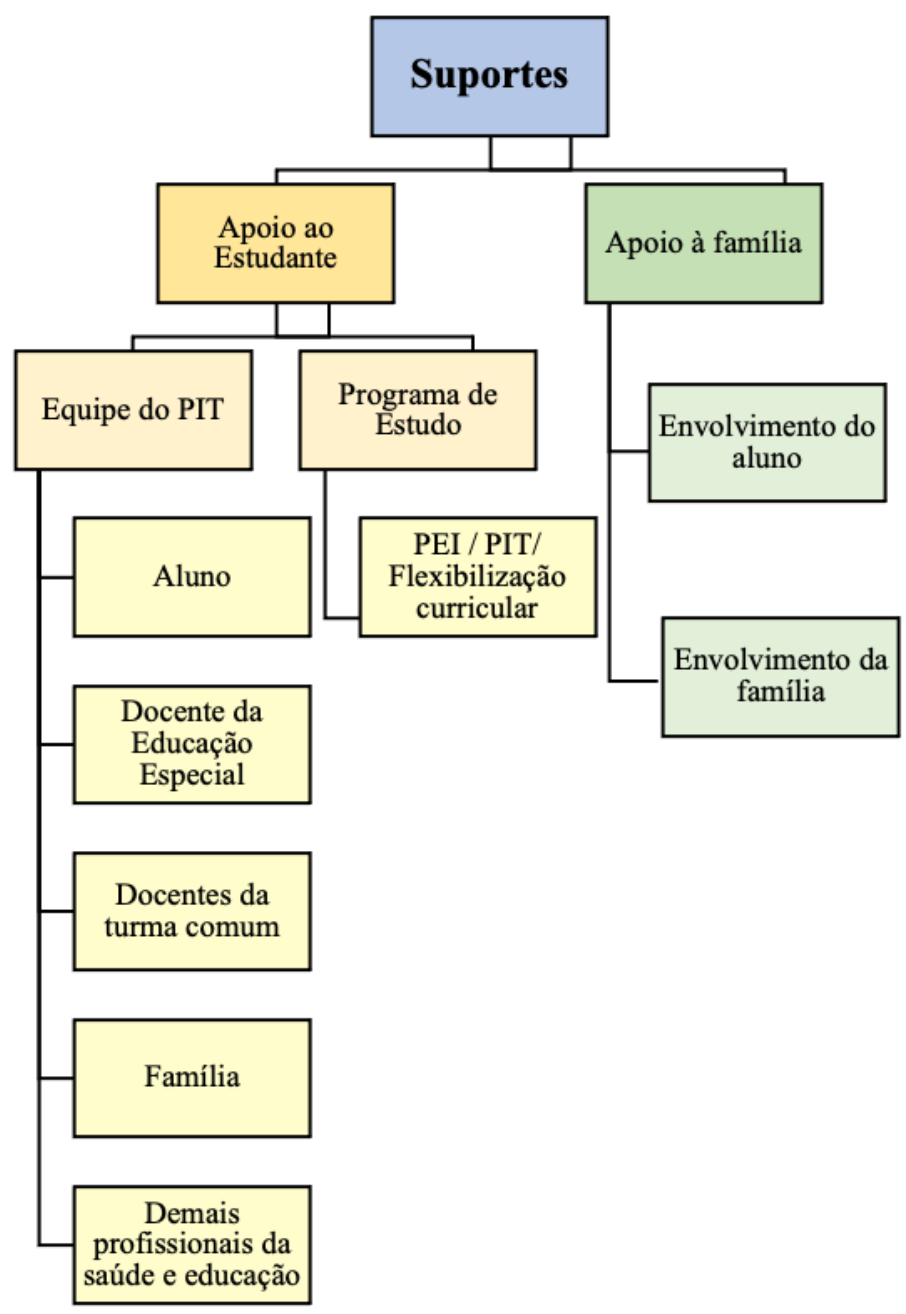

Fonte: A autora (2019).

De acordo com a figura 2, podemos perceber a importância do envolvimento da família e do aluno na construção e implementação do PIT, de forma que esse documento seja utilizado da melhor maneira possível. A família precisa conhecer este instrumento, auxiliar no seu desenvolvimento e acreditar na possibilidade de que esse sujeito seja inserido na comunidade de forma ativa e independente. Para isso, talvez seja preciso conscientizar da família, para que esta visualize os potenciais e competências da pessoa com deficiência, além de ajudar na busca de opções de inserção no trabalho, comunidade e formação profissional. 


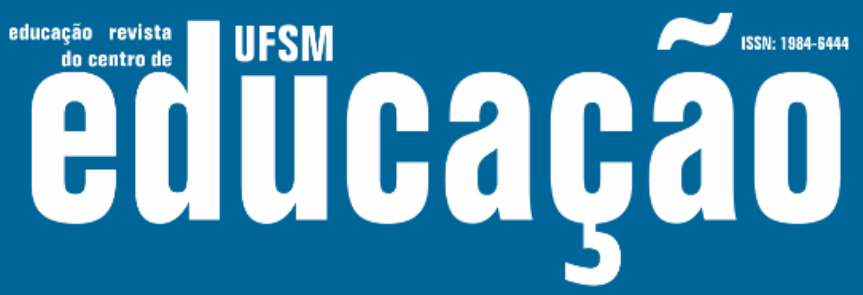

ISSN: 1984-6444 | http://dx.doi.org/10.5902/1984644443012

Após atingir as metas do PIT direcionadas para o processo de escolarização, o foco deverá ser nas habilidades necessárias para inclusão no mercado de trabalho ou progressão da vida acadêmica em outras modalidades como Educação Profissional ou Ensino Superior. Para metas direcionadas para a progressão acadêmica é fundamental realizar visitas, verificar as possibilidades de cursos e estabelecer as metas e ações para que o educando possa iniciar o curso desejado. Para a inserção no mercado de trabalho é imprescindível que possíveis empregadores estejam envolvidos neste processo, para possibilidades de estágios e contratação. Ao chegar neste nível (mundo do trabalho), o PIT deve ser reavaliado e a nova equipe montada com profissionais que possam fazer uma articulação, com a finalidade de capacitação e manutenção no emprego para os jovens.

A parceria com outras instituições passa a ser essencial, tanto instituições de formação profissionais quanto de empresas. Essa parceria servirá para que o educando com deficiência possa conhecer possibilidades de trabalho e decidir, a partir de suas habilidades e interesses, qual caminho seguir. Outro aspecto relevante é a conscientização do empregador e demais funcionários para a inclusão dessa população e dos seus potenciais, para que a contratação não seja feita apenas para o cumprimento da Lei de Cotas (BRASIL, 1991) e nem de forma assistencialista, mas devido ao fato desta pessoa ser capaz de cumprir suas funções e contribuir para o bom funcionamento da empresa (REDIG, 2014, 2016).

\section{Considerações finais}

Alles e Boueri (2018) fizeram uma pesquisa no portal de periódicos da CAPES, Education Resources Information Center (ERIC), Scientific Electronic Library Online (SCIELO), Scopus Preview e na Biblioteca Digital Brasileira de Teses e Dissertações (BDTD) sobre as produções dos últimos dez anos (2007 a 2017) em relação à deficiência intelectual e transição para a vida adulta e perceberam uma escassez de trabalhos nesta área e a necessidade de mais investigações sobre o assunto. 


\title{
Autharẫ
}

ISSN: 1984-6444 | http://dx.doi.org/10.5902/1984644443012

Alles e Boueri (2018, p.13) colocam que:

\begin{abstract}
O processo de TVA [transição para a vida adulta] ocorre numa fase decisiva na vida dos jovens sendo repleto de escolhas e decisões, que por vezes são definitivas para a formação profissional. A transição desse modo deve ser pensada e preparada tendo em consideração os desejos e aspirações dos jovens e de suas famílias. Por conseguinte, a escola necessita estar preparada e em articulação com profissionais, especialistas e todos os envolvidos no processo educacional para atender o jovem com deficiência. Assim, uma escola que pretende ser inclusiva deve garantir a cada estudante o direito à educação e à preparação para a integração social.
\end{abstract}

Assim, percebemos a importância de utilizar instrumentos como inventário de interesses e PPP para entender os desejos e interesses dos alunos com deficiência e desta forma, organizar o PIT, com a finalidade de auxiliar no processo de transição da escola para vida independente. Vale ressaltar, a importância de uma equipe de transição coesa que atue não somente na escola, no desenvolvimento de habilidades acadêmicas, sociais e laborais, mas também que ajude na busca de atividades de trabalho e capacitação profissional.

Essa equipe deve ser reestruturada toda vez em que as metas forem alteradas, pois como estas mudam, os profissionais envolvidos também poderão alterar, lembrando que o sujeito com deficiência e sua família sempre participarão deste processo. Ao ser incluído no mundo do trabalho, o empregador será inserido nesta equipe e, caso vá para cursos profissionalizantes, independentemente do nível, algum profissional deve fazer parte desta equipe, visto que, é preciso avaliar o progresso do indivíduo e se realmente esta é a área em que deve atuar.

A construção do PIT deve ser realizada de forma estruturada e cautelosa, com a finalidade de um projeto de vida, no qual haverá metas a serem alcançadas. Cada pessoa terá o seu próprio PIT, o qual atenderá as suas demandas, necessidades e interesses. De acordo com Lopes (2016, p.55), "a transição para a vida adulta é parte de uma etapa significativa da vida de uma pessoa, e cada passo precisa ser orientado de forma adequada para a obtenção de bons resultados e garantia de qualidade de vida para os jovens".

Concluímos que com a individualização do ensino aliada à acessibilidade pedagógica, a uma equipe capacitada e com um trabalho colaborativo, é possível 


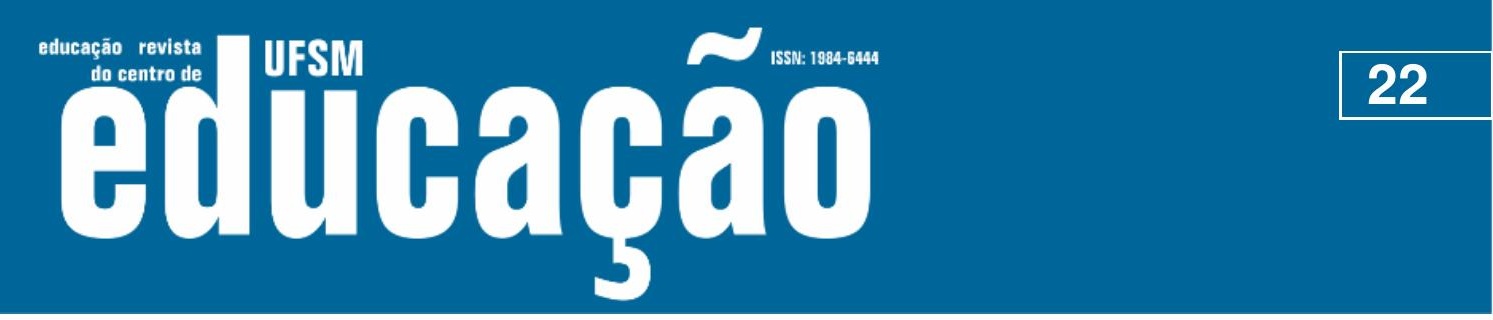

ISSN: 1984-6444 | http://dx.doi.org/10.5902/1984644443012

que estes educandos trilhem seus caminhos nos mais diferentes níveis de ensino e vida independente. É preciso, como já visto, de maiores investigações nesta temática e não existe um modelo único de PIT, pois cada instituição poderá elaborar um documento de acordo com a sua realidade. Entretanto, é fundamental esse documento para que esses sujeitos possam realmente ser inseridos na sociedade e ter uma vida independente, a partir de um percurso formativo que lhes permita guiar a sua trajetória escolar e de vida.

\section{Referências}

ALLES, Elisiane Perufo; BOUERI, lasmin Zanchi. Transição para a vida adulta e deficiência intelectual: uma revisão sistemática na literatura. Anais do VIII Congresso Brasileiro de Educação Especial. São Carlos: UFSCar, 2018.

BRASIL. Lei 8.213, de 24 de julho de 1991. Dispõe sobre os Planos de Benefícios da Previdência Social e dá outras providências.

BRASIL. Lei 9394, de 20 de dezembro de 1996. Lei de Diretrizes e Bases. Estabelece as diretrizes e bases da educação nacional.

BRASIL. Política Nacional de Educação Especial na Perspectiva da Educação Inclusiva. De 07 de janeiro de 2008.

BRASIL. Lei no 13.146, de 06 de julho de 2015. Institui a Lei Brasileira de Inclusão da Pessoa com Deficiência (Estatuto da Pessoa com Deficiência).

CARVALHO, Ana Cristina de. Plano Individual de Transição para vida adulta para pessoas com deficiência intelectual. (Dissertação do Curso de Mestrado Profissional em Diversidade e Inclusão). Universidade Federal Fluminense, Niterói, RJ, Brasil, 2018.

CTI, Center on Transition Innovations. Lesson Four Transcript. Postsecondary Education \& Training: Opening Doors to Opportunities. Virginia, EUA, 2018.

DANTAS, Dulciana de Carvalho Lopes. Estudante com deficiência intelectual no ensino superior: entre utopia e a realidade. In: MELO, Francisco-Ricardo Lins-Vieira de (Org.). Inclusão no ensino superior: docência e necessidades educacionais especiais. pp. 155-164. Natal: EDUFRN, Brasil, 2013. 


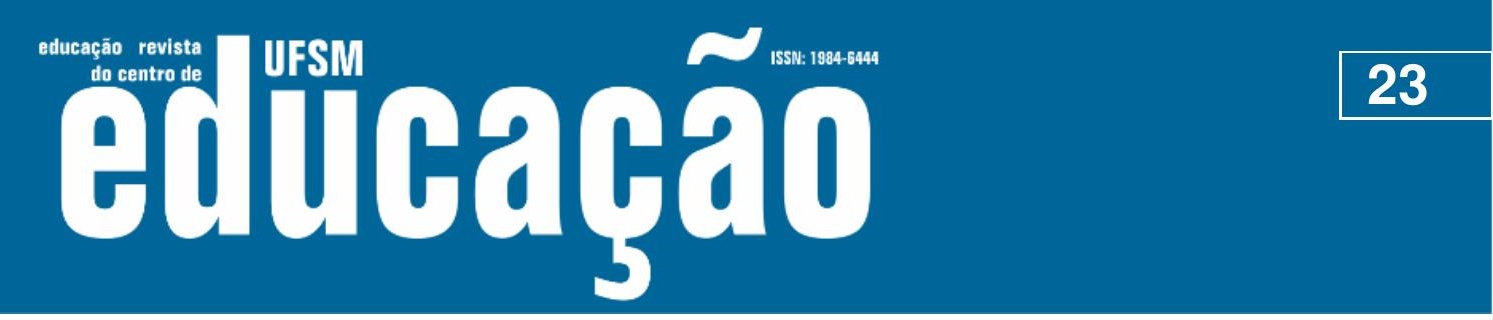

ISSN: 1984-6444 | http://dx.doi.org/10.5902/1984644443012

FÂNZERES, Luís José Leite Teixeira. Transição para a vida adulta de alunos com necessidades educativas especiais: percursos de formação no sistema educativo Português. (Tese do Curso de Doutorado). Instituto de Educação da Universidade do Minho, Portugal, 2017.

GLAT, Rosana. Desconstruindo representações sociais por uma cultura de colaboração para inclusão escolar. Revista Brasileira de Educação Especial. v.24, pp. 9-20. Marília, São Paulo, SP, Brasil, 2018.

INEP, Instituto Nacional de Estudos e Pesquisas Educacionais Anísio Teixeira. Sinopse estatística da Educação Básica 2011. Brasília, Brasil, 2012.

INEP, Instituto Nacional de Estudos e Pesquisas Educacionais Anísio Teixeira. Sinopse estatística da Educação Básica 2012. Brasília, Brasil, 2013.

INEP, Instituto Nacional de Estudos e Pesquisas Educacionais Anísio Teixeira. Sinopse estatística da Educação Básica 2013. Brasília, Brasil, 2014.

INEP, Instituto Nacional de Estudos e Pesquisas Educacionais Anísio Teixeira. Sinopse estatística da Educação Básica 2014. Brasília: Brasil, 2015.

INEP, Instituto Nacional de Estudos e Pesquisas Educacionais Anísio Teixeira. Sinopse estatística da Educação Básica 2015. Brasília, Brasil, 2016.

INEP, Instituto Nacional de Estudos e Pesquisas Educacionais Anísio Teixeira. Sinopse estatística da Educação Superior 2016. Brasília, Brasil, 2017.

INEP, Instituto Nacional de Estudos e Pesquisas Educacionais Anísio Teixeira. Sinopse estatística da Educação Superior 2017. Brasília, Brasil, 2018a.

INEP, Instituto Nacional de Estudos e Pesquisas Educacionais Anísio Teixeira. Sinopse estatística da Educação Básica 2017. Brasília, Brasil, 2018b.

INEP, Instituto Nacional de Estudos e Pesquisas Educacionais Anísio Teixeira. Sinopse estatística da Educação Básica 2018. Brasília, Brasil, 2019.

KOHLER, Paula D.; GOTHBERG, June E.; FOWLER, Catherine; COYLE, Jennifer. Taxonomy for transition programming 2.0: A model for planning, organizing, and evaluating transition education, services, and programs. Western Michigan University, 2016. Acessado em 03 de junho de 2019 de www.transitionta.org

LAGO, Danúsia Cardoso; MAYER, Maria Grazia Guillén. Inclusão no Mercado de trabalho das pessoas com deficiência intelectual: análise das teses e dissertações. In: COSTA, Maria da Piedade Resende da. A pessoa com deficiência no mercado de trabalho. p. 41-58. São Carlos: Pedro \& João Editores, 2012. 


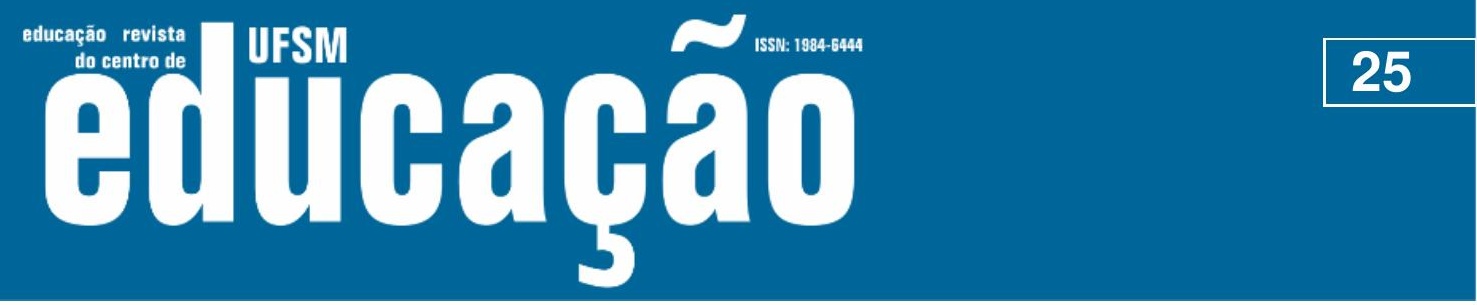

ISSN: 1984-6444 | http://dx.doi.org/10.5902/1984644443012

NASCIMENTO, Vanêssa Lima do. Um programa de formação docente para transição da escola para uma vida mais independente, para alunos com deficiência intelectual da EJA. (Tese de Qualificação de Mestrado) Programa de Pós Graduação em Educação da Universidade do Estado do Rio de Janeiro, Rio de Janeiro, RJ, Brasil, 2020.

PLETSCH, Márcia Denise. Repensando a inclusão escolar: diretrizes políticas, práticas curriculares e deficiência intelectual. 2. ed. Rio de Janeiro/RJ: NAU, 2014.

REDIG, Annie Gomes. Perfil Pessoal Positivo: estratégia para favorecer a inserção da pessoa com deficiência intelectual no mercado de trabalho. Anais IV Congresso Brasileiro de Educação Especial e VII Encontro Nacional dos Pesquisadores da Educação Especial. p. 1315-1330. São Carlos: UFSCar, 2012.

REDIG, Annie Gomes. Aplicação e análise de um programa customizado para a inclusão de jovens com deficiência intelectual em atividades laborais. (Tese de Doutorado) Programa de Pós Graduação em Educação da Universidade do Estado do Rio de Janeiro, Rio de Janeiro, RJ, Brasil, 2014.

REDIG, Annie Gomes. Inserção profissional de jovens e adultos com deficiência intelectual. Curitiba: Editora Appris, 2016.

REDIG, Annie Gomes. Caminhos formativos no contexto inclusivo para estudantes com deficiência e outras condições atípicas. Revista Educação Especial. v.32, pp. 1-19. Marília, São Paulo, SP, Brasil, 2019.

SORIANO, Victoria. Planos individuais de transição: apoiar a transição da escola para o emprego. European Agency for Development in Special Needs Education, 2006.

TANNÚS-VALADÃO, Gabriela. Planejamento educacional individualizado em Educação Especial: propostas oficiais da Itália, França, Estados Unidos e Espanha. (Dissertação de Mestrado) Universidade Federal de São Carlos, São Paulo, SP, Brasil, 2011.

U. S. Department of Education (Department), Office of Special Education and Rehabilitative Services. A Transition Guide to Postsecondary Education and Employment for Students and Youth with Disabilities, Washington, D.C., EUA, 2017.

VIRGINIA DEPARTMENT OF EDUCATION. Office of Special Education and Student Services. Transition Assessment: establishing a foundation for a successful transition to adulthood. Virginia, EUA, 2014. 


\section{ح

ISSN: 1984-6444 | http://dx.doi.org/10.5902/1984644443012

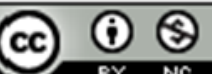

This work is licensed under a Creative Commons Attribution-NonCommercial 4.0 International (CC BY-NC 4.0)

\section{Notas}

\footnotetext{
1 Pesquisa com financiamento FAPERJ e Capes Print.

2 De acordo com a Política Nacional de Educação Especial na perspectiva da Educação Inclusiva (BRASIL, 2008) são considerados público-alvo da Educação Especial pessoas com deficiências física, sensorial, intelectual, transtorno do espectro autista, altas habilidades/superdotação.

${ }^{3}$ Dados referentes à sinopse estatística da Educação Básica 2018 (INEP, 2019).

${ }^{4}$ Dados referentes à sinopse estatística da Educação Superior 2017 (INEP, 2018).

${ }^{5} \mathrm{O}$ Plano de Ensino Individualizado (PEI) é um instrumento que normaliza a prática pedagógica de forma a elaborar um currículo individualizado e flexível para o aluno com deficiência. Para maiores informações, sugerimos a leitura Mascaro (2017), Tannús-Valadão (2011).

${ }^{6}$ Tradução livre.

${ }^{7}$ Modelo de PIT baseado em Carvalho (2018).
} 